\title{
Effect of orally administered aqueous extract of Salvia triloba L. in human volunteers
}

\section{Nessrin Ghazi Alabdallat}

Department of Medical Laboratory Sciences, Collae of Applied Medical Sciences, Majmaah University, AL-Majmaah 11952, S.A.

\begin{tabular}{|c|c|}
\hline Article Info & Abstract \\
\hline $\begin{array}{l}\text { Article history } \\
\text { Received } 1 \text { November } 2021 \\
\text { Revised } 16 \text { December } 2021 \\
\text { Accepted } 17 \text { December } 2021 \\
\text { Published Online } 30 \text { December } 2021\end{array}$ & $\begin{array}{l}\text { Salvia triloba L. belongs to the Lamiaceae family, is one in all the vital medicinal plant species. This work } \\
\text { aims to study the antioxidant related effects of } S \text {. triloba in the human body through in vivo study and the } \\
\text { effects on liver, kidney, and heart function tests. For five days, nine healthy participants consumed } 250 \\
\text { ml of } S \text {. triloba aqueous extract orally. Blood samples were taken before and one hour after the first dosage } \\
\text { of water extract (samples I and II, respectively), and again one day after the last dose (i.e., day } 6 \text {, sample }\end{array}$ \\
\hline $\begin{array}{l}\text { Keywords } \\
\text { Total antioxidant status } \\
\text { Superoxide dismutase } \\
\text { Serum biochemical test } \\
\text { Superoxide dismutase }\end{array}$ & $\begin{array}{l}\text { III). Before the first dosage, the first blood sample was taken (i.e., sample I) and was used as a control for } \\
\text { the subsequent II and III samples. Subsequent determinations were performed: serum total antioxidant } \\
\text { status (TAS), red blood cell reduced glutathione (RBC GSH), red blood cell superoxide dismutation (RBC SOD) } \\
\text { activity, red blood cell malondialdehyde (RBC MDA), and serum-selected biochemical tests. After } 5 \text { days of } \\
\text { oral administration of } S \text {. triloba extract in healthy volunteers, serum TAS, erythrocyte GSH and erythrocyte } \\
\text { SOD activity were significantly increased, and had no influence on serum biochemical examinations of } \\
\text { kidney, liver, heart, pancreas, etc., contrasted with zero-time dose. S. triloba extract has effective } \\
\text { antioxidation related effects in vivo. Because these findings were obtained in healthy people without } \\
\text { oxidative stress, it means that } S \text {. triloba will enhance the defense system against probable oxidative } \\
\text { damage and might be useful in avoiding pathological diseases related to oxidative damage. }\end{array}$ \\
\hline
\end{tabular}

\section{Introduction}

Salvia triloba L. (Lamiaceae), is commonly referred to as Greek sage and the arabic name of $S$. triloba is Meramiyyh (Abu-Rmailah and Afifi, 2000; Ali-Shtayeh et al., 2000). It is commonly used to treat bloating, stomach problems, abdominal pain, oral infections, gingiva and tooth pain, headaches, coughs, flu, common cold, skin diseases, and neurological diseases (Abu-Rmailah and Afifi, 2000; Ali-Shtayeh et al., 2000; Perry et al., 2003; Gali-Muhtasib and Affara, 2000; Salah and Jager, 2005). S. triloba extract has antioxidant, antiinflammatory, antibacterial and anticancer behaviors (Kamatou et al., 2010; Kamatou et al., 2008; Kamatou et al., 2007). In vitro pharmacological activity and chemical studies of some sage species are previously evaluated (Kamatou et al., 2005).

In human body, free radicals and reactive oxygen species are continually generated. This oxygen species are the source of cell damage as well as the onset and progression of chronic illnesses. Antioxidants defense mechanisms such as reduced glutathione (GSH), superoxide dismutase (SOD), glutathione peroxidase (GPx), glutathione reductase (GR), glutathione S-transferase (GST), and catalase, as well ascarotenoids and polyphenols, protected human body from oxidative damage (Valko et al., 2007).

Corresponding author: Dr. Nessrin Ghazi Alabdallat Department of Medical Laboratory Sciences, Collage of Applied Medical Sciences, Majmaah University, AL-Majmaah 11952, Saudi Arabia. E-mail: n.alabdallat@mu.edu.sa

Tel.: +966-164042869

Copyright (c) 2021 Ukaaz Publications. All rights reserved.

Email: ukaaz@yahoo.com; Website: www.ukaazpublications.com
The systemic effects are also important to understand if a plant extract affects laboratory analysis, because many patients may go to clinical laboratories for analysis after drinking plant extracts that have become widely available. This work aims to study the antioxidant effects of Meramiyyh in the human body through in vivo study and its effects on liver, kidney and heart function tests.

\section{Materials and Methods}

Nine healthy volunteers were recruited after signing the informed consent form according to the requirements of the ethics committee. Each volunteer took $250 \mathrm{ml}$ of Meramiyyh extract orally every day for five days. Blood samples were collected before and one hour after the first dosage of water extract (samples I and II, respectively), and then one day after the last dose on the fifth day (i.e., day 6 , sample III). The initial blood sample (sample I) taken before to the first dosage was utilized as a control for the subsequent samples II and III. This study was carried out in line with the 1964 Declaration of Helsinki's ethical standards.

\subsection{Formulation of Meramiyyh water extract}

The dried leaves were acquired in Amman, Jordan, at a small herbal shop. 250 grams of leaves was boiled for 10-15 min, then left covered soaking at room temperature for 3-4 h, then $250 \mathrm{ml}$ of soaked aqueous extract was given orally to each individual daily for 5 days.

\subsection{Sample of blood}

Three blood samples (I, II and III) were collected from each healthy individual in the gel clot activator tubes. These were centrifuged at $3000 \mathrm{rpm}$ for $10 \mathrm{~min}$ at $25^{\circ} \mathrm{C}$ to separate and collect serum. After 
that, $2 \mathrm{ml}$ of distilled water added to the cells in the tube under the gel, and tubes were centrifuged at $3000 \mathrm{rpm}$ for $5 \mathrm{~min}$, and the supernatant was collected. Before analysis, all samples were kept frozen at $-20^{\circ} \mathrm{C}$ until analysis.

\subsection{Serum TAS determination}

The total antioxidant status of serum was measured by Randox's TAS kit. The results are expressed in millimoles per litre $(\mathrm{mmol} / \mathrm{l})$.

\subsection{MDA levelsin red blood cells}

MDA in red blood cells was determined as a measure of lipid peroxidation according to Stocks and Dormandy's method (1971) using thiobarbituric acid (TBA) as modified by Srour et al. (2000). All MDA values are given in nanomoles per gram of hemoglobin $(\mathrm{nmol} / \mathrm{gHb})$

\subsection{GSH levels in red blood cells}

The Ellman technique, with minor changes, was used to measure red blood cell GSH, as reported elsewhere (Bilto and Alabdallat, 2015a). All GSH values are measured in $\mathrm{mg} / \mathrm{gHb}$.

\subsection{RBC SOD activity determination}

Randox kit (Arthur et al., 1985) was used to test RBC SOD. The result is given in units of $\mathrm{U} / \mathrm{gHb}$.

\subsection{Biochemical parameters of serum determination}

The following biochemical parameters were determined using the Hitachi 902 analyzer: serum sodium (Na), potassium (K), urea nitrogen (BUN), creatinine (CREA), uric acid (UA), albumin (ALB), total protein (TP), alkaline phosphatase (ALP), lactate dehydrogenase (LDH), alanine transaminase (ALT), aspartate transaminase (AST), creatinine phosphokinase (CPK), amylase (AMYL).

\subsection{Numerical evaluation}

All data are presented as mean \pm standard deviation and statistical analysis is carried out with the help of the social science statistical package (SPSS, 17th edition). The results were compared by paired t-test. The results with a value of $p \leq 0.05$ were considered significant.

\section{Results}

The results are shown in Table 1. Serum total antioxidant status (TAS) (from 1.12 to 1.22), red blood cell reduced glutathione (GSH) (from 0.54 to 0.87 ) and erythrocyte superoxide dismutation (SOD) (from 868 to 997.5 ) are all higher on day 6 after oral intake of Meramiyyh extract in healthy volunteers for five days as compared to zero time of oral intake. Meramiyyh had no effect on serum readings that stayed within the reference range $(\mathrm{Na}, \mathrm{K}, \mathrm{BUN}, \mathrm{CREA}$, UA, ALB, TP, ALP, ALT, AST, AMYL, are all tested at zero-time, 1 hour after the first dose and 1 day after the final dose on day 5).

Table 1: Results of in vivo research of oral administration of Meramiyyh aqueous extract in healthy volunteers for 5-days. Each statistic reflects the mean \pm standard deviation $(n=9)$, with a $* p$ value $\leq 0.05$, compared to 0 time dose. NM stands for "not measured."

\begin{tabular}{|l|c|c|c|}
\hline Measurement parameters & Sample I & Sample II & Sample III \\
\hline Serum TAS (mmol/l) & $1.12 \pm 0.11$ & $1.16 \pm 0.15$ & $1.22 \pm 0.16^{*}$ \\
Erythrocyte GSH (mg/gHb) & $0.54 \pm 0.09$ & $\mathrm{NM}$ & $0.87 \pm 0.10^{*}$ \\
Erythrocyte SOD (U/gHb) & $868.0 \pm 167.1$ & $\mathrm{NM}$ & $997.5 \pm 192.4^{*}$ \\
Erythrocyte MDA (nmol/gHb) & $17.9 \pm 3.4$ & $\mathrm{NM}$ & $15.8 \pm 3.8$ \\
Serum K (ref value=3.7-5.2 mmol/l) & $4.38 \pm 0.40$ & $4.4 \pm 0.2$ & $4.34 \pm 0.38$ \\
Serum Na (ref value=135-145mmol/l) & $146.0 \pm 2.2$ & $144 \pm 1.2$ & $145.4 \pm 1.7$ \\
Serum BUN (ref value=6-20 mg/dl) & $13.5 \pm 3.5$ & $13.0 \pm 2.8$ & $9.7 \pm 2.0$ \\
Serum CREA (ref value=0.6-1.3 mg/dl) & $0.74 \pm 0.13$ & $0.72 \pm 0.13$ & $0.65 \pm 0.16$ \\
Serum UA (ref value=3.5-7.2 mg/dl) & $4.92 \pm 1.0$ & $5.0 \pm 1.0$ & $5.4 \pm 1.3$ \\
Serum ALB (ref value=34-54 g/l) & $45.2 \pm 2.2$ & $44.6 \pm 2.5$ & $46.6 \pm 3.8$ \\
Serum TP (ref value $=60-85 \mathrm{~g} / \mathrm{l})$ & $77.6 \pm 3.9$ & $76.1 \pm 2.1$ & $79.7 \pm 4.4$ \\
Serum ALP (ref value=55-142 U/l) & $112.9 \pm 71.5$ & $110.3 \pm 67.2$ & $112.0 \pm 78.3$ \\
Serum AST (ref value=8-40 U/l) & $15.8 \pm 5.7$ & $16.2 \pm 5.0$ & $16.4 \pm 5.4$ \\
Serum ALT (ref value= 7-55 U/l) & $17.4 \pm 13.3$ & $17.5 \pm 14.1$ & $18.9 \pm 15.7$ \\
Serum CPK (ref value=38-176 U/l) & $90.5 \pm 65.7$ & $93.0 \pm 64.4$ & $80.5 \pm 35.8$ \\
SerumLDH (refvalue=200-450 U/l) & $307.3 \pm 48.0$ & $317 \pm 48.2$ & $304.4 \pm 39.7$ \\
Serum AMY (refvalue=40-140 U/l) & $46.8 \pm 15.2$ & $45.9 \pm 14.7$ & $43.3 \pm 16.6$ \\
\hline
\end{tabular}

\section{Discussion}

According to current in vivo human research, oral intake of Meramiyyh extract for five days can considerably improve TAS, RBC reduced glutathione (GSH) and RBC superoxide dismutas.
Because the current study's findings were achieved in healthy persons who had not been exposed to oxidative stress, it is likely that Meramiyyh might enhance the baseline of the defense system against oxidative stress, lowering the risk of oxidative stress-related illnesses. 
The lack of effect of Meramiyyh on serum LDH in healthy individuals might imply that the plant has antihemolytic action and/or no deleterious hemolytic activity in vivo. Serum biochemical assays show that oral Meramiyyh extract had no significant impact on the renal function tests (CREA, BUN), liver function enzymes and tests (AST, ALT,ALP, ALB, TP), myocardial enzymes and pancreatic amylase which are all within the reference ranges. This finding agrees with the findings of Moeko et al., 2015; Alabdallat, 2016; Alabdallat, 2019.

Lifestyle factors like nutrition, physical activity, drinking and smoking have been proposed to have a major impact on human oxidative stress and disrupt oxidative balance. As a result of the burden/ antioxidant interaction, it has been shown that a diet high in vegetables and natural antioxidants is good to antioxidants and is most popular among healthy people who live long lives (Dato et al., 2013; Aseervatham et al., 2013).

\section{Conclusion}

The active antioxidant effects of Meramiyyh on healthy people have no negative effects on the main body system, implying that this plant can be used to prevent the onset or progression of oxidative stress-related pathological conditions by improving the body's defense mechanism's bottom line.

\section{Authors' contributions}

NA was in charge of the study's design as well as data collecting, processing, and analysis. The final version of the manuscript was written by NA, who also authorized it.

\section{Acknowledgements}

The author is thankful to the Deanship of Scientific Research at Majmaah University for supporting this work under Project Number No. R-2021-271.

\section{Conflict of interest}

The author declares no conflicts of interest relevant to this article.

\section{References}

Alabdallat, N.G. (2019). In vivo antioxidant-related effect of orally administered ground seeds of Nigella sativa in human volunteers. International Journal of Pharmaceutical and Phytopharmacological Research, 9(6):95-98.

Alabdallat, N.G. (2016). In vivo antioxidant related effects of orally administered aqueous extract of lemon balm (Melissa officinalis 1.) in human. International Journal of Pharma and Biosciences, 7(3): (B):642-645.

Ali-Shtayeh, M.S.; Yaniv, Z. and Mahajna, J. (2000). Ethnobotanical survey in the Palestinian area: A classification of the healing potential of medicinal plants. J. Ethnopharmacol., 73:221-232.
Arthur, J.R. and Boyne, R. (1985). Superoxide dismutase and glutathione peroxidase activities in neutrophilis from selenium deficient and copper deficient cattle. Life Sci., 36:156-975.

Aseervatham, G. S. B.; Sivasudha, T.; Jeyadevi, R. and Arul Ananth, D. (2013). Environmental factors and unhealthy lifestyle influence oxidative stress in humans: An overview. Environmental Science and Pollution Research, 20(7):4356-4369.

Abu-Rmailah, B. and Afifi, F. (2000). Treatment with medicinal plants in Jordan., Dirasat. medical and biological Sciences, 27:53-74.

Dato, S.; Crocco, P.; D’Aquila, P.; de Rango, F.; Bellizzi, D.; Rose, G. and Passarino, G. (2013). Review: Exploring the role of genetic variability and lifestyle in oxidative stress response for healthy ageing and longevity. Int. J. Mol. Sci., 14:16443-16472.

Ellman, G.L. (1951). Tissue sulfhydryl (-SH) groups. Archive of Biochemistry and Biophysiology, 82:70-77.

Gali-Muhtasib, H.U. and Affara, N.I. (2000). Chemopreventive effects of sage oil on skin papillomas in mice. Phytomedicine, 7:129-136.

Kamatou, G.P.P.; Van Vuuren, S.F.; Van Heerden, F.R.; Seaman, T. and Viljoen, A.M. (2007). Antibacterial and antimycobacterial activities of South African Salvia species and isolated compounds from $S$. chamelaeagnea. South African Journal of Botany, 73:552-557.

Kamatou, G.P.P.; Van Zyl, R.L.; Davids, H.; Van Heerden, F.R.; Lourens, A.C.U. and Viljoen, A.M. (2008). Antimalarial and anticancer activities of selected South African Salvia species and isolated compounds from S. radula. South African Journal of Botany, 74:238-243.

Kamatou, G.P.P.;Viljoen, A.M.; Gono-Bwalya, A.B.; van Zyl, R.L.; van Vuuren, S.F.;Lourens, A.C.U.; Ba ${ }^{0}$ er, K.H.C.; Demirci, B.; Lindsey, K.L.; van Staden, J. and Steenkamp, P. (2005). The in vitro pharmacological activities and a chemical investigation of three South African Salvia species. Journal of Ethnopharmacology, 102:382-390.

Kamatou, G.P.P.; Viljoen, A.M. and Steenkamp, P. (2010). Antioxidant, antiinflammatory activities and HPLC analysis of South African Salvia species. Food Chemistry, 119:684-688.

Moeko, N.; Kenjiro, O.; Tsuyoshi, H., K. I.; Toshitada, N.; Shoko, K.; Hiroyuki, N. and Masahito, Y. (2015). Pharmacokinetics, safety and tolerability of Melissa officinalis extract which contained rosmarinic acid in healthy individuals: A randomized controlled trial. PLoS One, 10(5): e0126422.

Perry, N.S.; Bollen, C.; Perry, E.K. and Ballard, C. (2003). Salvia for dementia therapy: Review of pharmacological activity and pilot tolerability clinical trial. Pharmacology, Biochemistry and Behavior., 75:651659.

Salah, S.M. and Jager, A.K. (2005). Screening of traditionally used Lebanese herbs for neurological activities. J. Ethnopharmacol., 97:145-149.

Srour, M.A.; Bilto, Y.Y. and Juma, M. (2000). Evaluation of different methods used to measure malonyldialdehyde in human erythrocytes. Clin. Hemorheol. Microcirc, 23:23-30.

Valko, M.; Leibfritz, D.; Moncol, J.; Cronin, M.T.; Mazur, M. and Telser, J. (2007). Free radicals and antioxidants in normal physiological functions and human disease. Int. J. Biochem. Cell Biol., 39:44-84. 